\title{
EFEITO DA CALAGEM E SULFATO DE AMÔNIO NO ALGODÃO. II - CONCENTRAÇÃO DE CÁTIONS E ÂNIONS NA SOLUÇÃO DO SOLO E ABSORÇÃO DE NUTRIENTES PELAS PLANTAS ${ }^{(1)}$
}

\author{
José Salvador Simoneti Foloni ${ }^{(2)}$, Ciro Antonio \\ $\operatorname{Rosolem}^{(3)} \&$ Rodrigo Arroyo Garcia ${ }^{(4)}$
}

\begin{abstract}
RESUMO
No sistema de semeadura direta, o calcário tem sido aplicado superficialmente para evitar o revolvimento do solo. Os ânions adicionados via adubação nitrogenada podem aumentar a solubilização de sais de cátions básicos do solo graças à formação de pares iônicos. O objetivo deste trabalho foi estudar a dinâmica dos ânions $\mathrm{NO}_{3}{ }^{-}$ e $\mathrm{SO}_{4}{ }^{2-} \mathrm{e}$ dos cátions $\mathrm{NH}_{4}{ }^{+}, \mathrm{Ca}^{2+}, \mathrm{Mg}^{2+} \mathrm{e} \mathrm{K} \mathrm{K}^{+}$da solução do solo, bem como a absorção de nutrientes pelo algodoeiro submetido a distintas formas de aplicação de calcário e diferentes doses de sulfato de amônio em cobertura, cultivado com a presença de palha na superfície do solo. Utilizou-se um Latossolo Vermelho distroférrico de textura média que foi acomodado em vasos com $15,71 \mathrm{dm}^{3}$. Plantas de algodão (Gossypium hirsutum) foram cultivadas por 60 dias nas condições de calagem superficial sobre a palha, calagem incorporada a $0-20 \mathrm{~cm}$ de profundidade e ausência de correção do solo, com a aplicação de doses de sulfato de amônio equivalentes a 0, 50, 100 e $150 \mathrm{~kg} \mathrm{ha}^{-1}$ de $\mathrm{N}$ em cobertura. Cápsulas porosas foram instaladas para amostragem e quantificação de nutrientes da solução do solo. A concentração de $\mathrm{SO}_{4}{ }^{2-}$ da solução do solo foi incrementada pela adubação nitrogenada, independentemente da forma de aplicação do calcário. A curto prazo, a nitrificação do $\mathrm{NH}_{4}{ }^{+}$aplicado foi favorecida somente com a calagem incorporada, apesar de o $\mathrm{N}$ nítrico da solução do solo ter aumentado no final do cultivo do algodão até mesmo no solo não corrigido. As concentrações de Ca, Mg e K da solução do solo foram incrementadas pela adubação de cobertura. $\mathrm{O}$ ânion $\mathrm{SO}_{4}{ }^{2-}$ apresentou maior afinidade do que o $\mathrm{NO}_{3}{ }^{-}$na formação de pares iônicos com os cátions básicos da solução do solo. A adubação nitrogenada proporcionou maior eficiência na absorção de Ca e Mg pelo algodoeiro na condição de calagem incorporada.
\end{abstract}

Termos de indexação: cálcio, magnésio, potássio, nitrato, plantio direto.

\footnotetext{
(1) Recebido para publicação em abril de 2004 e aprovado em março de 2006.

(2) Professor da Faculdade de Agronomia, Campus II, Universidade do Oeste Paulista - UNOESTE. Rodovia Raposo Tavares, km 572, CEP 19067-175 Presidente Prudente (SP). E-mail: sfoloni@unoeste.br

(3) Professor Titular Departamento de Produção Vegetal-FCA, Universidade do Estado de São Paulo - UNESP. Caixa Postal 237, CEP 18603-970 Botucatu (SP). E-mail: rosolem@fca.unesp.br

(4) Graduando em Agronomia do Departamento de Produção Vegetal-FCA, UNESP. Bolsista do CNPq-PIBIC. E-mail: ragarcia@fca.unesp.br
} 


\title{
SUMMARY: EFFECT OF LIMING AND AMMONIUM SULFATE IN COTTON. II - CONCENTRATION OF CATIONS AND ANIONS IN THE SOIL SOLUTION AND PLANT NUTRIENT UPTAKE
}

\begin{abstract}
In no-tillage systems lime is applied on the soil surface to avoid soil mobilization. Nitrogen fertilization adds anions that can increase the solubility of basic cations of the soil due to formation of ionic pairs. The objective of this study was to characterize the dynamics of anions $\left(\mathrm{SO}_{4}{ }^{2-}\right.$ and $\left.\mathrm{NO}_{3}{ }^{-}\right)$and cations $\left(\mathrm{NH}_{4}{ }^{+}, \mathrm{Ca}^{2+}, \mathrm{Mg}^{2+}\right.$ and $\left.\mathrm{K}^{+}\right)$in the soil solution, and the nutrient uptake by cotton plants subjected to different lime application forms and ammonium sulfate fertilization, with straw on the soil surface. Cotton plants (Gossypium hirsutum) were grown for 60 days in PVC columns filled with a distroferric Red Latosol (sand loam Rhodic Oxisol). The soil had lime incorporated into the 0-20 cm layer, liming on the soil surface, or received no lime. Nitrogen was used at rates of $0,50,100$ and $150 \mathrm{~kg} \mathrm{ha}^{-1}$ as ammonium sulfate. The pots consisted of PVC columns of $20 \mathrm{~cm}$ diameter and $50 \mathrm{~cm}$ height, totaling $15.71 \mathrm{dm}^{3}$. Porous capsules were installed at a depth of 15-20 cm to extract soil solution. The $\mathrm{SO}_{4}{ }^{2-}$ of the soil solution was increased by the nitrogen fertilization, independently of the lime application form. Nitrification was favored in the short-term with the application of ammonium sulfate only in the condition of incorporated lime. After 50 days of plant growth, however, nitrate in the soil solution increased, even in the soil that had not been limed. The Ca, $\mathrm{Mg}$ and $\mathrm{K}$ concentrations in the soil solution were increased as a response to the nitrogen top dressing. The anion $\mathrm{SO}_{4}{ }^{2-}$ presented greater affinity than $\mathrm{NO}_{3}{ }^{-}$in the formation of ionic pairs with the basic cations in the soil solution. The application of ammonium sulfate was most effective in promoting Ca and Mg uptake by the cotton plants when lime was incorporated.
\end{abstract}

Index terms: calcium, magnesium, potassium, nitrate, no-tillage.

\section{INTRODUÇÃO}

Os nutrientes imediatamente disponíveis às plantas são aqueles que se encontram em solução, oriundos da fase sólida do solo ou dos fertilizantes. Por sua vez, a disponibilização dos íons para as raízes depende de diversos fatores, tais como: $\mathrm{pH}$, complexação iônica, conteúdo de água, precipitação e dissolução de sólidos, temperatura, profundidade, capacidade de troca catiônica, potencial de oxirredução, atividade biológica e matéria orgânica do solo (Sposito, 1989). Segundo Raij (1991), os cátions e os ânions da solução do solo ocorrem em quantidades estequiometricas, e este fato é importante nos processos de troca iônica, acidificação, disponibilidade de nutrientes às plantas e perdas por lixiviação.

Os ânions $\mathrm{SO}_{4}{ }^{2-}$ e $\mathrm{NO}_{3}{ }^{-}$provenientes da mineralização dos resíduos orgânicos e dos fertilizantes podem promover, em determinadas condições, a movimentação descendente dos cátions básicos $\left(\mathrm{Ca}^{2+}\right.$, $\mathrm{Mg}^{2+} \mathrm{e} \mathrm{K}^{+}$) no perfil, em virtude da associação iônica na solução do solo com a neutralização momentânea de cargas (Pearson et al., 1962; Oliveira et al., 2002). Além disso, a resposta das plantas a determinado elemento químico pode ser alterada pela formação de par iônico com outro elemento de carga oposta na solução do solo (Chaves et al., 1991).
A calagem é prática usual para correção da acidez do solo, porém os materiais corretivos utilizados são pouco solúveis em água e os produtos da reação do calcário têm ação limitada às camadas superficiais do solo (Ritchey et al., 1980; Caires et al., 1999). Segundo Vitti et al. (1986), as solubilidades em água, a $20-25{ }^{\circ} \mathrm{C}$, do carbonato de cálcio $\left(\mathrm{CaCO}_{3}\right)$ e do sulfato de amônio $\left[\left(\mathrm{NH}_{4}\right)_{2} \mathrm{SO}_{4}\right]$ são de 0,014 e $754 \mathrm{~g} \mathrm{~L}^{-1}$, respectivamente. Portanto, a dissolução do fertilizante sulfato de amônio é bastante expressiva, o que confere a esta fonte de $\mathrm{N}$, comumente utilizada na agricultura brasileira, uma alta capacidade de fornecer ânions $\mathrm{SO}_{4}{ }^{2-}$ ao solo em curto prazo, considerando, ainda, o potencial de formação de ânions $\mathrm{NO}_{3}^{-}$, com a nitrificação do $\mathrm{NH}_{4}{ }^{+}$aplicado. Conseqüentemente, segundo Lindsay (1979), um aumento na oferta de ânions na solução do solo, gerado pela adubação nitrogenada por exemplo, pode intensificar a solubilização de carbonatos, para que ocorra o restabelecimento do equilíbrio eletroquímico da solução do solo.

A aplicação de sulfato de amônio causa rápida queda do $\mathrm{pH}$ do solo (Strong et al., 1997) e são precisos $110 \mathrm{~kg}$ de $\mathrm{CaCO}_{3}$ para neutralizar a acidez gerada por $100 \mathrm{~kg}$ de $\left(\mathrm{NH}_{4}\right)_{2} \mathrm{SO}_{4}$ aplicados (Vieira \& Ramos, 1999). Por outro lado, a calagem favorece a formação de $\mathrm{NO}_{3}{ }^{-}$no solo, visto que a taxa de nitrificação é prejudicada em $\mathrm{pH}$ em água menor do que 6,0 e é 
insignificante em $\mathrm{pH}$ inferior a 4,5 (Adams \& Martim, 1984). Além disso, segundo Camargo \& Raij (1989), em solos ácidos, com predomínio de cargas variáveis, quando os valores de $\mathrm{pH}$ são baixos, a carga líquida, quando negativa, é baixa, podendo até ser positiva nos colóides do solo, o que diminui a retenção de ânions, como o $\mathrm{SO}_{4}{ }^{2-}$ e o $\mathrm{NO}_{3}^{-}$, e, quando a calagem é praticada, há aumento na adsorção de cátions básicos, provocado pela liberação de cargas negativas dependentes de $\mathrm{pH}$.

No que diz respeito ao algodão, conforme Silva (1999), vários experimentos de longa duração demonstraram que a calagem promove aumentos expressivos na produtividade desta cultura e os melhores desempenhos ocorreram quando a saturação por bases foi elevada a $60 \%$, mesmo em solos com baixos teores iniciais de $\mathrm{Al}$ trocável. Por outro lado, Silva et al. (1995) observaram que a deficiência de K no algodoeiro foi mais severa em áreas calcariadas que não receberam adubação potássica, em relação às plantas de algodão cultivadas na ausência de calagem e sem aplicação de K. De acordo com Marschner (1995), a competição entre nutrientes por sítios de troca da membrana plasmática das células radiculares acontece particularmente entre íons com propriedades fisico-químicas semelhantes, como o $\mathrm{NH}_{4}{ }^{+}$que, em algumas situações, inibe a absorção de $\mathrm{K}^{+}$pelas raízes, ou no caso do $\mathrm{Mg}^{2+}$, que sofre forte competição por sítios de troca do tecido radicular com o $\mathrm{Ca}^{2+} \mathrm{e} \mathrm{o} \mathrm{K}^{+}$, e vice-versa.

Objetivou-se, neste trabalho, estudar a dinâmica dos ânions $\mathrm{NO}_{3}{ }^{-}$e $\mathrm{SO}_{4}{ }^{2-}$ e dos cátions $\mathrm{NH}_{4}{ }^{+}, \mathrm{Ca}^{2+}, \mathrm{Mg}^{2+}$ e $\mathrm{K}^{+}$na solução do solo, bem como a absorção de nutrientes pelo algodoeiro, submetido a distintas formas de aplicação de calcário, adubado com diferentes doses de sulfato de amônio em cobertura e cultivado com palha na superfície do solo.

\section{MATERIAL E MÉTODOS}

O experimento foi realizado em casa de vegetação do Departamento de Produção Vegetal, da Faculdade de Ciências Agronômicas, UNESP, em Botucatu, SP. Utilizou-se terra coletada de 0-20 $\mathrm{cm}$ de profundidade de um Latossolo Vermelho distroférrico (Carvalho et al., 1983; Embrapa, 1999) de textura média (660 g kg-1 de areia, $280 \mathrm{~g} \mathrm{~kg}^{-1}$ de argila e $60 \mathrm{~g} \mathrm{~kg}^{-1}$ de silte). A terra foi seca ao ar e passada em peneira com malha de $4 \mathrm{~mm}$. A análise química (Raij \& Quaggio, 1983) revelou os seguintes valores: $\mathrm{pH}\left(\mathrm{CaCl}_{2} 1 \mathrm{~mol} \mathrm{~L}^{-1}\right) 3,7$; $34 \mathrm{~g} \mathrm{dm}^{-3}$ de M.O.; 3,0 $\mathrm{mg} \mathrm{dm}^{-3}$ de Presina; $135 \mathrm{mmol}_{\mathrm{c}} \mathrm{dm}^{-3} \mathrm{de} \mathrm{H}+\mathrm{Al} ; 0,6 \mathrm{mmol}_{\mathrm{c}} \mathrm{dm}^{-3}$ de K ; 4,0 $\mathrm{mmol}_{\mathrm{c}} \mathrm{dm}^{-3}$ de $\mathrm{Ca} ; 1,0 \mathrm{mmol}_{\mathrm{c}} \mathrm{dm}^{-3} \mathrm{de} \mathrm{Mg}$; 5,6 $\mathrm{mmol}_{\mathrm{c}} \mathrm{dm}^{-3}$ de SB; $140 \mathrm{mmol}_{\mathrm{c}} \mathrm{dm}^{-3}$ de CTC e $4 \%$ de saturação por bases (V).

A capacidade de campo do solo desestruturado (peneirado) foi determinada a -0,03 MPa no aparelho extrator de Richards (Embrapa, 1997), e o valor encontrado foi de $180 \mathrm{~g} \mathrm{~kg}^{-1}$. Aplicou-se o equivalente a 2,8 $\mathrm{t} \mathrm{ha}^{-1}$ de calcário dolomítico (CaO: $28 \%, \mathrm{MgO}$ : $20 \%$, PN: $99 \%$ e PRNT: $95 \%)$ em toda a terra peneirada, antes de se iniciar o experimento, uma vez que a saturação por bases e o $\mathrm{pH}$ eram inadequados para o cultivo do algodoeiro. A terra corrigida foi mantida em sacos de plástico por 30 dias com o teor de água a $180 \mathrm{~g} \mathrm{~kg}^{-1}$ (capacidade de campo). Em seguida, o solo foi seco ao ar novamente e adubado

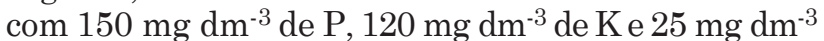
de $\mathrm{N}$, nas formas de $\mathrm{KH}_{2} \mathrm{PO}_{4} \mathrm{e} \mathrm{NH}_{4} \mathrm{H}_{2} \mathrm{PO}_{4}$. Foram aplicados $2,0 \mathrm{mg} \mathrm{dm}^{-3}$ de $\mathrm{B}, 2,0 \mathrm{mg} \mathrm{dm}^{-3}$ de $\mathrm{Mn}$, $6,0 \mathrm{mg} \mathrm{dm}^{-3}$ de $\mathrm{Zn} \mathrm{e} 1,5 \mathrm{mg} \mathrm{dm}^{-3}$ de $\mathrm{Cu}$, como $\mathrm{H}_{3} \mathrm{BO}_{3}$, $\mathrm{MnSO}_{4}, \mathrm{ZnSO}_{4}$ e $\mathrm{CuSO}_{4}$, respectivamente.

Os vasos foram montados, utilizando cinco anéis de PVC rígido sobrepostos, com $20 \mathrm{~cm}$ de diâmetro interno, correspondendo às seguintes profundidades: 0-5, 5-10, 10-20, 20-30 e 30-50 cm, totalizando $15,71 \mathrm{dm}^{3}$. A terra foi acondicionada nos vasos de forma a ser estabelecida uma densidade de $1,2 \mathrm{~kg} \mathrm{dm}^{-3}$, correspondente às condições de campo. Para simular a cobertura do solo, utilizou-se palha de milheto picada em pedaços de 2 a $4 \mathrm{~cm}$, seca em estufa de aeração forçada a $60^{\circ} \mathrm{C}$, por $72 \mathrm{~h}$, em quantidade equivalente a 4 t ha $^{-1}$.

Os tratamentos constituíram-se de três formas de aplicação de calcário (sem calcário, calcário superficial - em cima da palha e calcário incorporado de 0-20 cm de profundidade) e quatro doses de $\mathrm{N}$ aplicadas em cobertura $\left(0,50,100\right.$ e $\left.150 \mathrm{~kg} \mathrm{ha}^{-1}\right)$, como sulfato de amônio. Utilizou-se, nesta etapa, o mesmo calcário dolomítico descrito anteriormente, numa dose correspondente a $5 \mathrm{t} \mathrm{ha}^{-1}$, que, somada à dose de $2,8 \mathrm{t} \mathrm{ha}^{-1}$, aplicada anteriormente, completou $7,8 \mathrm{t} \mathrm{ha}^{-1}$ de corretivo, correspondente à quantidade recomendada para elevar a saturação por bases a $60 \%$ (Quaggio \& Raij, 1996). O calcário foi aplicado dez dias antes da semeadura do algodão (Gossypium hirsutum, var. IAC-22), de acordo com os tratamentos. As doses de sulfato de amônio foram calculadas, considerando um cultivo de algodoeiro com espaçamento entre linhas de $0,90 \mathrm{~m}$, aplicando-se a quantidade correspondente a $0,20 \mathrm{~cm}$ de linha a cada vaso, de acordo com seu diâmetro. A aplicação do adubo nitrogenado foi parcelada aos 20 e 40 dias da emergência das plântulas (DAE). Foram cultivadas duas plantas por vaso, cortadas aos 60 DAE. A umidade do solo foi controlada diariamente por meio de pesagem dos vasos e da reposição da água evapotranspirada até $180 \mathrm{~g} \mathrm{~kg}^{-1}$.

Cápsulas de porcelana porosa com $21 \mathrm{~mm}$ de diâmetro externo por $58 \mathrm{~mm}$ de comprimento foram instaladas entre 15-20 $\mathrm{cm}$ de profundidade, em todos os vasos. Imediatamente após saturar o solo, até atingir a umidade equivalente à capacidade de campo, foram realizadas extrações da solução do solo por meio de pressão negativa de 60 a $80 \mathrm{kPa}$, produzida por bomba elétrica, aos 25 e 50 DAE. As quantidades de solução do solo extraídas foram padronizadas em $60 \mathrm{~mL}$ por vaso e mantidas sob refrigeração a $2{ }^{\circ} \mathrm{C}$ até análise. Foram determinados os teores de $\mathrm{S}_{-} \mathrm{SO}_{4}{ }^{2-}$, 
$\mathrm{Ca}^{2+}, \mathrm{Mg}^{2+}$ e $\mathrm{K}^{+}$das amostras de solução do solo por meio de espectrofotometria de emissão atômica em plasma, enquanto os teores de nitrato $\left(\mathrm{N}^{-} \mathrm{NO}_{3}{ }^{-}\right)$e amônio $\left(\mathrm{N}^{-} \mathrm{NH}_{4}{ }^{+}\right)$foram quantificados por destilação a vapor (Cantarella \& Trivelin, 2001). Considerando a densidade do solo peneirado, acomodado nos vasos, de $1,2 \mathrm{~kg} \mathrm{dm}^{-3}$, e o conteúdo de água na capacidade de campo de $180 \mathrm{~g} \mathrm{~kg}^{-1}$, calcularam-se as concentrações dos nutrientes na solução do solo. Foram ainda determinados a massa da matéria seca e os acúmulos de $\mathrm{Ca}, \mathrm{Mg}$ e K na parte aérea das plantas de algodão, de acordo com Malavolta et al. (1997).

O experimento, fatorial $3 \times 4$, foi disposto em blocos ao acaso, com quatro repetições. Foram feitas análises de regressão e ajustadas equações lineares ou quadráticas significativas até $5 \%$ pelo teste $\mathrm{F}$, que apresentaram os maiores coeficientes de determinação $\left(\mathrm{R}^{2}\right)$. Fez-se também um estudo de correlação linear para pares de íons da solução do solo aos 25 e $50 \mathrm{DAE}$ do algodoeiro, sendo os coeficientes de correlação testados a $5 \%$.

\section{RESULTADOS E DISCUSSÃO}

A adubação de cobertura com sulfato de amônio proporcionou aumentos expressivos nas concentrações de $\mathrm{SO}_{4}{ }^{2-}$ na solução do solo, tanto aos $25 \mathrm{DAE}$ como aos 50 DAE do algodão, para todas as condições de calagem (Figura 1a). Contudo, o uso de calcário não incrementou a solubilização de S, pois, na ausência da adubação nitrogenada, aos 25 DAE do algodão, as concentrações de $\mathrm{S}_{-} \mathrm{SO}_{4}{ }^{2-}$ da solução do solo foram de 5 , 7, e $13 \mathrm{mg} \mathrm{L}^{-1}$ para a calagem superficial, incorporada e sem o uso de corretivo, respectivamente, e aos $50 \mathrm{DAE}$, as concentrações foram de 6,9 e $16 \mathrm{mg} \mathrm{L}^{-1} \mathrm{de}$ $\mathrm{SO}_{4}{ }^{2-}$ na solução do solo para a calagem incorporada, superficial e ausência de corretivo, respectivamente (Figura 1a). Segundo Moreira \& Siqueira (2002), em torno de $90 \%$ do $\mathrm{S}$ total contido na camada arável (0-20 cm de profundidade) encontra-se na forma orgânica, e a mineralização do $\mathrm{S}$ orgânico, segundo Alvarez V. (1988), tende a ser maior nos solos que recebem calagem (por causa do aumento da atividade microbiana), o que efetivamente não foi observado no presente estudo, em termos de disponibilização de $\mathrm{SO}_{4}{ }^{2-}$ na solução do solo (Figura 1a).

As respostas do $\mathrm{SO}_{4}{ }^{2-}$ da solução do solo à adubação nitrogenada foram quadráticas nas condições de calagem incorporada e superficial, tanto aos $25 \mathrm{DAE}$ como aos $50 \mathrm{DAE}$ do algodão, e, na ausência de correção do solo, os incrementos foram lineares (Figura 1a). Portanto, quando se aplicou o corretivo, com destaque para a calagem incorporada, provavelmente houve aumento nas perdas de $\mathrm{SO}_{4}{ }^{2-}$ por lixiviação na presença de altas doses de sulfato de amônio, uma vez que, de acordo com Camargo \& Raij (1989), em solos ácidos, com predomínio de cargas variáveis, quando os valores de $\mathrm{pH}$ são baixos, há maior retenção de ânions nos colóides. Outro fator que pode ter contribuído para a diminuição das concentrações de $\mathrm{S}_{-} \mathrm{SO}_{4}{ }^{2-}$ das soluções dos solos que receberam calcário incorporado e superficial é que, com a aplicação de calcário, ocorreram maiores acúmulos de $\mathrm{S}$ na parte aérea do algodão (Figura 3a), em comparação às plantas cultivadas sem calagem, na presença de altas doses de adubação nitrogenada.

A concentração de $\mathrm{NO}_{3}{ }^{-}$na solução do solo aos 25 DAE do algodão foi influenciada pela aplicação de sulfato de amônio somente quando o calcário foi incorporado (Figura 1b). Segundo Adams \& Martim (1984), a formação de $\mathrm{NO}_{3}$ ' no solo é prejudicada em $\mathrm{pH}$ menor do que 6,0 e é insignificante em $\mathrm{pH}$ inferior a 4,5. Portanto, a mistura do corretivo ao solo provavelmente acelerou as reações de neutralização da acidez e, por conseqüência, favoreceu a atividade das bactérias nitrificadoras, tornando ágil a conversão do $\mathrm{NH}_{4}{ }^{+}$em $\mathrm{NO}_{3}{ }_{3}^{-}$. Em contrapartida, aos $50 \mathrm{DAE}$, as concentrações de $\mathrm{N}_{-} \mathrm{NO}_{3}$ 'da solução da camada arável foram aumentadas pela adubação nitrogenada até mesmo na ausência de aplicação do corretivo (Figura 1b). No entanto, de acordo com as equações de regressão ajustadas, quando se aplicou a maior dose de sulfato de amônio em cobertura (150 kg ha-1 de N), as concentrações de $\mathrm{N}^{-\mathrm{NO}_{3}}$ da solução da camada arável foram de 31,28 e $17 \mathrm{mg} \mathrm{L}^{-1}$, para a calagem superficial, ausência de correção do solo e calagem incorporada, respectivamente. Sendo assim, no final do ciclo de cultivo do algodão (50 DAE), a incorporação do calcário pode ter proporcionado perdas relativamente maiores de $\mathrm{NO}_{3}{ }^{-}$por lixiviação, decorrentes da menor capacidade de retenção de ânions no solo corrigido até $20 \mathrm{~cm}$ de profundidade (Camargo \& Raij, 1989) e da maior eficiência na absorção de N pelo algodoeiro cultivado no solo que apresentou $\mathrm{pH}$ mais elevado (Rosolem et al., 2003).

A concentração de $\mathrm{N}-\mathrm{NH}_{4}{ }^{+}$da solução na camada arável foi incrementada com o aumento da adubação nitrogenada de cobertura, tanto aos $25 \mathrm{DAE}$ como aos 50 DAE do algodão, com respostas bem mais expressivas nas condições de calagem superficial e na ausência de correção do solo (Figura 1c). $\mathrm{O} \mathrm{N}-\mathrm{NH}_{4}{ }^{+}$ da solução do solo apresentou concentrações relativamente baixas, quando o calcário foi incorporado. Portanto, a oferta de $\mathrm{NH}_{4}{ }^{+}$solúvel na camada arável do solo mostrou-se bastante dependente da forma de aplicação do corretivo. Segundo Strong et al. (1997), a adubação com sulfato de amônio causa rápida queda no $\mathrm{pH}$ do solo, e Adams \& Martim (1984) relataram que a acidez inibe a produção de $\mathrm{NO}_{3}{ }^{-}$em solos que recebem aplicação de $\mathrm{NH}_{4}{ }^{+}$. No trabalho de Rosolem et al. (2003), aos 60 dias de cultivo do algodão, quando foram aplicadas as maiores doses de sulfato de amônio em cobertura, equivalentes a 100 e $150 \mathrm{~kg} \mathrm{ha}^{-1}$ de N, com a calagem incorporada conseguiu-se manter o $\mathrm{pH}$ do solo estável e mais elevado nas camadas de $5-10 \mathrm{~cm}$ e de $10-20 \mathrm{~cm}$ de profundidade no perfil, em comparação à calagem superficial e ao tratamento sem calagem. 

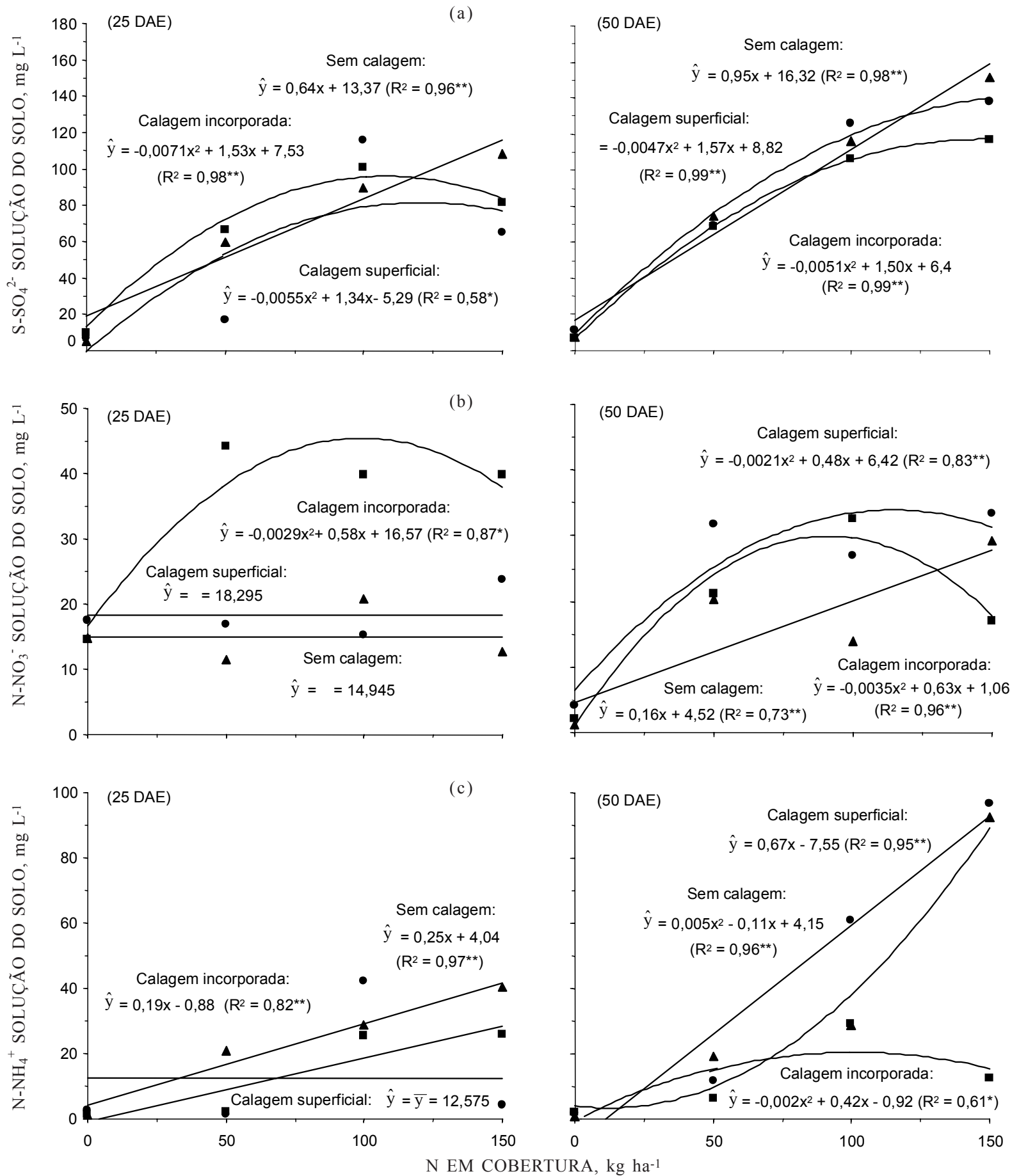

Figura 1. Concentrações de $\mathrm{S}_{-} \mathrm{SO}_{4}{ }^{2-}(\mathrm{a}), \mathrm{N}_{-} \mathrm{NO}_{3}{ }^{-}$(b) e N-NH${ }_{4}{ }^{+}$(c) na solução do solo, em função das doses de $\mathrm{N}$ aplicadas em cobertura, nas condições de calagem superficial (๑), calagem incorporada (口) e sem calagem ( $\Lambda$ ), aos 25 e 50 DAE do algodão. * e ** significativos a 5 e 1 \%, respectivamente. ns: não-significativo.

As concentrações de $\mathrm{Ca}^{2+}$ na solução do solo do presente experimento foram aumentadas pela adubação de cobertura com sulfato de amônio, aos 25 e 50 DAE do algodão, para todas as condições de calagem; contudo, as respostas foram bem mais expressivas, quando o corretivo foi incorporado ao solo
(Figura 2a). Segundo Lindsay (1979), um aumento na oferta de ânions na solução do solo pode intensificar a solubilização de sais, como por exemplo os de carbonato, para que ocorra o restabelecimento do equilíbrio eletroquímico. Os ânions $\mathrm{SO}_{4}{ }^{2-}$ e $\mathrm{NO}_{3}{ }^{-}$, provenientes da mineralização dos resíduos orgânicos e, ou, dos 
fertilizantes, podem promover a movimentação descendente de cátions de caráter básico no perfil, pela associação iônica na solução do solo com a neutralização momentânea de cargas (Pearson et al., 1962; Oliveira et al., 2002). No trabalho de Blevins et al. (1983), observaram-se, após 10 anos de cultivo de milho no sistema de semeadura direta, sem aplicação de calcário, perdas acentuadas de Ca trocável do solo, com reduções que foram de 55 para $12 \mathrm{mmol}_{\mathrm{c}} \mathrm{dm}^{-3}$, na camada de $0-5 \mathrm{~cm}$ de profundidade, e de 60 para $19 \mathrm{mmol}_{\mathrm{c}} \mathrm{dm}^{-3}$, na camada de $5-15 \mathrm{~cm}$ no perfil, quando as doses de nitrato de amônio, aplicadas em cobertura, foram aumentadas de 0 para $336 \mathrm{~kg} \mathrm{ha}^{-1} \mathrm{de} \mathrm{N}$. Tais autores atribuíram a exaustão de $\mathrm{Ca}^{2+}$ das camadas mais superficiais do solo à presença de íons acompanhantes gerados pela adubação nitrogenada, que promoveram a lixiviação dos cátions de caráter básico.
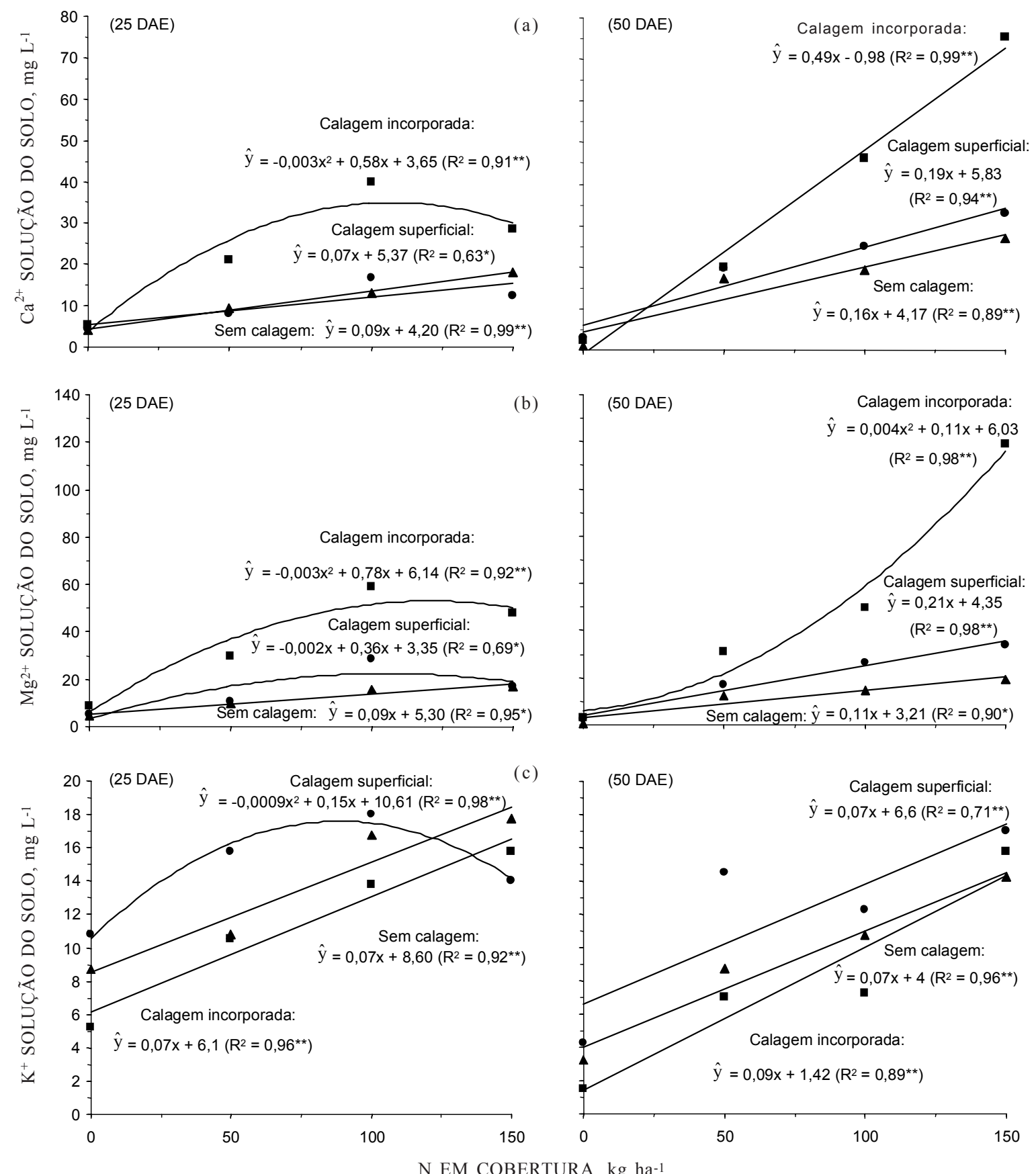

N EM COBERTURA, kg ha-1

Figura 2. Concentrações de cálcio (a), magnésio (b) e potássio (c) da solução do solo, em função das doses de $\mathrm{N}$ aplicadas em cobertura, nas condições de calagem superficial (๑), calagem incorporada ( $\square$ ) e sem calagem ( $\triangle$ ), aos 25 e 50 DAE do algodão. * e ** significativos a 5 e $1 \%$, respectivamente. ns: nãosignificativo. 
As concentrações de $\mathrm{Mg}^{2+}$ da solução do solo também foram influenciadas pela adubação nitrogenada de cobertura para todas as condições de calagem, aos 25 e 50 DAE do algodão (Figura 2 b). No entanto, a solubilização de $\mathrm{Mg}^{2+}$ na camada arável foi bem maior, quando o corretivo foi incorporado, da mesma forma que ocorreu com o $\mathrm{Ca}^{2+}$ (Figura 2a). Sendo assim, ficou evidente que a mistura do calcário ao solo, na profundidade de $0-20 \mathrm{~cm}$, intensificou os processos de reação dos carbonatos de cálcio e magnésio, favorecendo a solubilização destes cátions básicos. Nos trabalhos de Caires et al. (1999) e Caires et al. (2003), a lixiviação de $\mathrm{Mg}$ trocável foi intensificada ao longo do perfil do solo graças ao uso de gesso agrícola $\left(\mathrm{CaSO}_{4} \cdot 2 \mathrm{H}_{2} \mathrm{O}\right)$, tanto na condição de calagem superficial como na calagem incorporada, mesmo 40 meses após a aplicação do corretivo. Ernani \& Barber (1993) verificaram que as aplicações dos sais $\mathrm{CaSO}_{4}$ e $\mathrm{CaCl}_{2}$ proporcionaram aumentos nas concentrações de $\mathrm{Ca}^{2+} \mathrm{e} \mathrm{Mg}^{2+}$ na solução do solo, e os incrementos foram mais expressivos na presença do $\mathrm{CaCl}_{2}$, que foram justificados de acordo com a maior atividade química do cloreto de cálcio. No trabalho de Rosolem \& Machado (1984), em solo com poder-tampão relativamente baixo, houve intensa lixiviação de $\mathrm{K}^{+} \mathrm{e}$ $\mathrm{Mg}^{2+}$ com a aplicação de doses de $\mathrm{CaSO}_{4} \cdot 2 \mathrm{H}_{2} \mathrm{O}$. Pearson et al. (1962) observaram que as concentrações de $\mathrm{Ca}+\mathrm{Mg}$ da solução do solo tratado com calagem incorporada e adubação nitrogenada foram, em média, oito vezes superiores às do solo da testemunha (ausência de calagem e sem adição de N), e a adubação com sulfato de amônio neste trabalho intensificou a movimentação descendente de bases trocáveis no perfil do solo.

A cobertura com sulfato de amônio no algodão elevou as concentrações de $\mathrm{K}^{+}$na solução do solo aos 25 e $50 \mathrm{DAE}$, em todas as condições de calagem (Figura 2c). Seguindo a mesma argumentação feita para o $\mathrm{Ca}^{2+}$ e o $\mathrm{Mg}^{2+}$, a solubilização do $\mathrm{K}^{+}$na camada arável pode ter sido incrementada para favorecer 0 equilíbrio químico da solução do solo com a formação de pares iônicos (Lindsay, 1979), graças à maior oferta de $\mathrm{SO}_{4}{ }^{2-}$ e $\mathrm{NO}_{3}{ }^{-}$gerada pela adubação de cobertura. Outro ponto relevante diz respeito à exaustão de $\mathrm{K}^{+}$ da solução do solo que ocorreu no algodão cultivado sem adubação nitrogenada (Figura 2c). Ou seja, na ausência de aplicação de sulfato de amônio, a concentração média de $\mathrm{K}^{+}$solúvel aos $25 \mathrm{DAE}$ do algodão foi duas vezes superior à do $\mathrm{K}^{+}$coletado aos $50 \mathrm{DAE}$, em todas as condições de calagem. Este resultado pode ser justificado, de acordo com argumentação de Marschner (1995), por causa do excesso de $\mathrm{NH}_{4}{ }^{+}$, que, dependendo da situação, inibe a absorção de $\mathrm{K}^{+}$pelas raízes, pois estes dois cátions monovalentes competem por sítios de troca da membrana plasmática das células radiculares, por possuírem propriedades fisico-químicas semelhantes. Na figura 3-d, observa-se que, de maneira geral (com exceção do tratamento com $150 \mathrm{~kg} \mathrm{ha}^{-1}$ de $\mathrm{N}$ na condição de calagem superficial), a cobertura com sulfato de amônio não favoreceu o acúmulo de K na parte aérea do algodão, apesar de ter proporcionado um forte incremento de $\mathrm{K}^{+}$na solução do solo (Figura 2c), o que reforça a hipótese de inibição competitiva do $\mathrm{NH}_{4}{ }^{+}$sobre o cátion monovalente $\mathrm{K}^{+}$.

No quadro 1, estão apresentados os coeficientes de correlação linear calculados para pares de íons da solução do solo aos 25 e $50 \mathrm{DAE}$ do algodão. No primeiro estádio de avaliação (25 DAE), as correlações feitas com o ânion $\mathrm{NO}_{3}$ - foram significativas somente na condição de calagem incorporada. Em contrapartida, aos $50 \mathrm{DAE}$, a única situação em que não houve correlação significativa entre os cátions básicos e o $\mathrm{NO}_{3}{ }^{-}$da solução da camada arável foi quando o corretivo foi incorporado ao solo. Sendo assim, ficou evidente que o $\mathrm{N}^{-} \mathrm{NO}_{3}{ }^{-}$da solução do solo sofreu forte influência da forma de aplicação de calcário, da mesma forma que foi apresentado na figura $1 \mathrm{~b}$.

Por outro lado, as correlações entre o ânion $\mathrm{SO}_{4}{ }^{2-} \mathrm{e}$ os cátions básicos solúveis do solo foram altamente significativas em todas as condições de calagem, tanto aos 25 como aos 50 DAE do algodão (Quadro 1). Portanto, o $\mathrm{SO}_{4}{ }^{2-}$ da solução do solo, em comparação ao $\mathrm{NO}_{3}^{-}$, apresentou maior afinidade em formar pares iônicos com os cátions básicos solúveis da camada arável, além de ter-se mantido mais estável em relação à forma de aplicação de calcário. De acordo com Raij (1991), a maior disponibilização de $\mathrm{SO}_{4}{ }^{2-}$ nas camadas superficiais dos solos cultivados é favorecida pela calagem e pela matéria orgânica, que reduzem a adsorção deste ânion aos óxidos de ferro e alumínio, bem como pela presença dos ânions fosfatos adicionados via adubação, que ocupam, preferencialmente, os sítios de troca dos óxidos de ferro e alumínio em detrimento dos sulfatos.

$\mathrm{O}$ acúmulo de $\mathrm{S}$ na parte aérea do algodão, nas condições de calagens superficial e incorporada, apresentou resposta linear positiva com o aumento das doses de sulfato de amônio aplicadas em cobertura (Figura 3a). Por sua vez, no tratamento que não recebeu calcário, a absorção de $\mathrm{S}$ pelo algodoeiro apresentou resposta quadrática, com decréscimo na presença de altas doses de sulfato de amônio. Portanto, apesar de ter havido maior oferta de $\mathrm{SO}_{4}{ }^{2-}$ na solução do solo, quando foram aplicados $150 \mathrm{~kg} \mathrm{ha}^{-1}$ de N na ausência de calagem (Figura 1a), a absorção de S pelas plantas nesta condição pode ter sido prejudicada pela elevada acidez do solo. De acordo com estudo de Rosolem et al. (2003), um solo de textura média, com acidez não corrigida, que recebeu doses de até $150 \mathrm{~kg} \mathrm{ha}^{-1} \mathrm{de}$ $\mathrm{N}$ na forma de sulfato de amônio, apresentou valores de $\mathrm{pH}$ da camada arável que variaram de 4,0 a 5,0, condição considerada inadequada para o cultivo do algodão. Segundo Raij (1991), um dos fatores mais importantes de acidificação do solo é a nitrificação do $\mathrm{NH}_{4}{ }^{+}$oriundo da matéria orgânica e, ou, dos fertilizantes nitrogenados, que libera dois íons $\mathrm{H}^{+}$na solução do solo para cada molécula de $\mathrm{NH}_{4}{ }^{+}$ 
transformada em $\mathrm{NO}_{3}{ }^{-}$. Silva (1999) relatou que, em solos ácidos, o desenvolvimento radicular do algodoeiro era severamente prejudicado pelos baixos teores de
Ca e ocorria efeito tóxico no algodão quando o $\mathrm{pH}$ em água do solo era inferior a 5,5-5,2, em virtude do aumento da atividade do $\mathrm{Al}$ e do $\mathrm{Mn}$.

Quadro 1. Coeficientes de correlação linear calculados para pares de íons da solução do solo, nas condições de calagem superficial, calagem incorporada e sem calagem, considerando todas as doses de $\mathrm{N}$ aplicadas em cobertura

\begin{tabular}{|c|c|c|c|c|c|c|c|c|c|}
\hline \multirow{2}{*}{ Ânion } & \multicolumn{3}{|c|}{ Calagem superficial } & \multicolumn{3}{|c|}{ Calagem incorporada } & \multicolumn{3}{|c|}{ Sem calagem } \\
\hline & $\mathrm{Ca}^{2+}$ & $\mathrm{Mg}^{2+}$ & $\mathbf{K}^{+}$ & $\mathrm{Ca}^{2+}$ & $\mathrm{Mg}^{2+}$ & $\mathbf{K}^{+}$ & $\mathrm{Ca}^{2+}$ & $\mathbf{M g}^{2+}$ & $\mathbf{K}^{+}$ \\
\hline & \multicolumn{9}{|c|}{$25 \mathrm{DAE}$} \\
\hline $\mathrm{N}-\mathrm{NO}_{3} \cdot$ & $0,11^{\mathrm{ns}}$ & $0,05^{\mathrm{ns}}$ & $-0,15^{\mathrm{ns}}$ & $0,60^{*}$ & $0,60^{*}$ & $0,64^{* *}$ & $0,07^{\mathrm{ns}}$ & $0,28^{\mathrm{ns}}$ & $0,49^{\mathrm{ns}}$ \\
\hline \multirow[t]{2}{*}{$\mathrm{S}-\mathrm{SO}_{4}{ }^{2-}$} & $0,81^{* * *}$ & $0,77 * * *$ & $0,62^{* *}$ & $0,77 * * *$ & $0,70 * *$ & $0,72^{* *}$ & $0,82 * * *$ & $0,71^{* *}$ & $0,63^{* *}$ \\
\hline & \multicolumn{9}{|c|}{$50 \mathrm{DAE}$} \\
\hline $\mathrm{N}-\mathrm{NO}_{3}$ & $0,82^{* * *}$ & $0,71^{* *}$ & $0,92 * * *$ & $0,37^{\mathrm{ns}}$ & $0,13^{\mathrm{ns}}$ & $0,09^{\mathrm{ns}}$ & $0,88^{* * *}$ & $0,89 * * *$ & $0,81 * * *$ \\
\hline $\mathrm{S}-\mathrm{SO}_{4}{ }^{2-}$ & $0,82^{* * *}$ & $0,80 * * *$ & $0,78 * * *$ & $0,76^{* * *}$ & $0,65^{* *}$ & $0,54^{*}$ & $0,89 * * *$ & $0,92 * * *$ & $0,90 * * *$ \\
\hline
\end{tabular}

$.{ }^{*}, * *$ e ${ }^{* * *}$ significativos a 5,1 e $0,1 \%$ pelo teste t, respectivamente. ns: não-significativo.

(a)

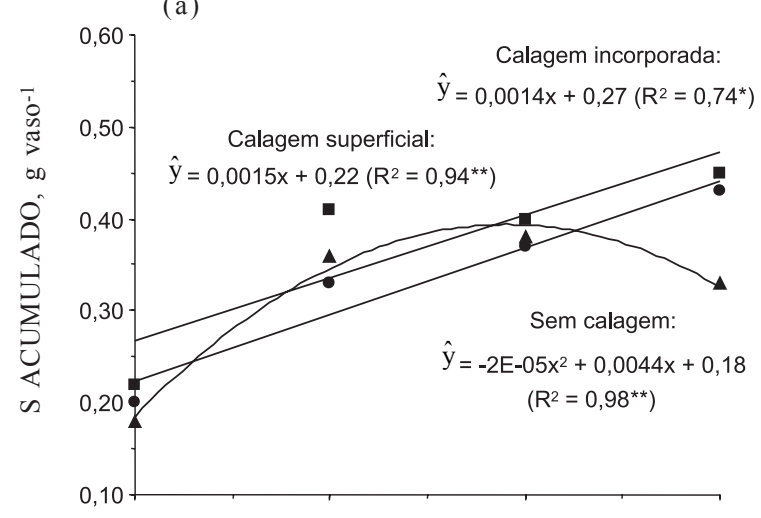

(c)

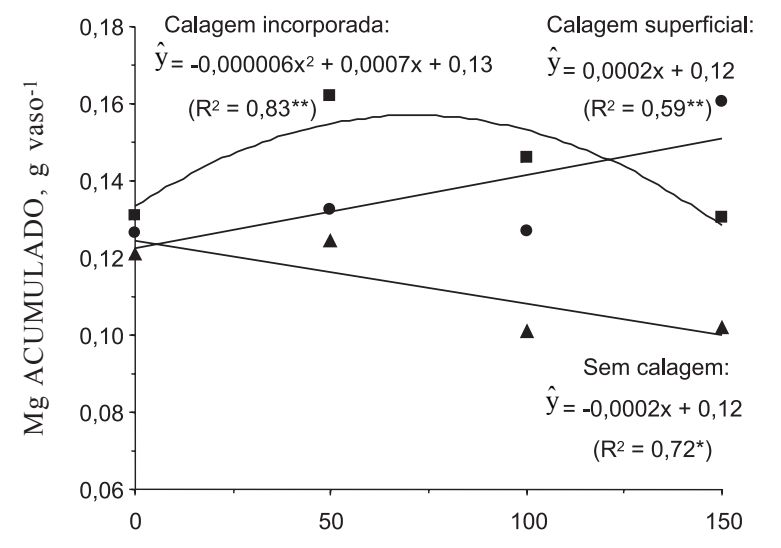

(b)

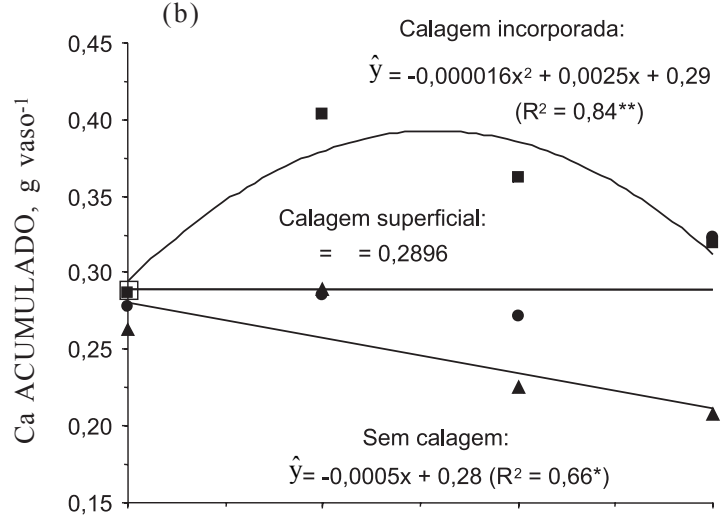

(d)

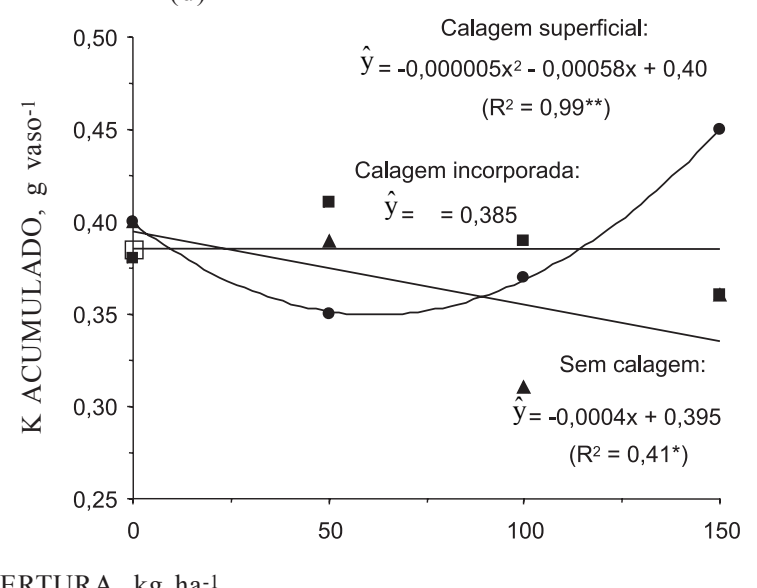

Figura 3. Acúmulo de enxofre (a), cálcio (b), magnésio (c) e potássio (d) na parte aérea das plantas de algodão, em função das doses de $\mathrm{N}$ aplicadas em cobertura, nas condições de calagem superficial (๑), calagem incorporada $(\square)$ e sem calagem $(\Delta)$. * e* significativos a 5 e $1 \%$, respectivamente. ns: nãosignificativo. 
A adubação de cobertura com sulfato de amônio, quando não foi corrigida a acidez do solo, prejudicou consideravelmente o acúmulo de $\mathrm{Ca}, \mathrm{Mg}$ e $\mathrm{K}$ na parte aérea das plantas de algodão (Figuras 3b, 3c e 3d). No trabalho de Rosolem et al. (2000), a absorção de cátions básicos pelas raízes do algodoeiro foi bastante prejudicada na condição de alta acidez do solo, pois, ao realizarem calagem para elevar a saturação por bases de 10 para $70 \%$, observou-se que a absorção de nutrientes por unidade de comprimento radicular do algodão foi aumentada, no caso do $\mathrm{Ca}$, de 0,8 para $1,6 \mathrm{mg} \mathrm{m}^{-1} \mathrm{e}$, no caso do $\mathrm{Mg}$, de 0,1 para $0,2 \mathrm{mg} \mathrm{m}^{-1}$. No caso do K do presente trabalho, na ausência de correção do solo, a adubação com sulfato de amônio proporcionou aumentos de até 3,6 vezes no teor de $\mathrm{K}^{+}$ da solução do solo (Figura 2c). No entanto, o acúmulo de K na parte aérea do algodoeiro foi prejudicado com o aumento da adubação nitrogenada no solo sem calagem (Figura 3d). Ou seja, apesar de a adubação com sulfato de amônio ter aumentado a oferta de $\mathrm{K}^{+}$ na solução do solo, houve menor absorção deste cátion pelas plantas, provavelmente graças à inibição competitiva promovida pelo $\mathrm{NH}_{4}{ }^{+}$aplicado (Marschner, 1995).

$\mathrm{O}$ acúmulo de Ca na parte aérea do algodão foi incrementado pela adubação nitrogenada de cobertura somente na condição de calagem incorporada (Figura 3b). Por sua vez, o acúmulo de $\mathrm{Mg}$ no algodoeiro foi aumentado pela aplicação de $\mathrm{N}$, tanto na calagem incorporada como na calagem superficial (Figura 3c). No entanto, de acordo com as equações de regressão ajustadas, quando o calcário foi incorporado, o acúmulo máximo de $\mathrm{Mg}$ na parte aérea do algodoeiro foi de $0,15 \mathrm{~g} \mathrm{vaso}^{-1}$, com uma aplicação da ordem de $58 \mathrm{~kg} \mathrm{ha}^{-1}$ de N, e, na condição de calagem superficial, o maior acúmulo de $\mathrm{Mg}$ no algodão também foi de $0,15 \mathrm{~g}$ vaso $^{-1}$, porém, alcançado somente com $150 \mathrm{~kg} \mathrm{ha}^{-1}$ de N. Sendo assim, a adubação de cobertura com sulfato de amônio proporcionou maior eficiência na absorção de $\mathrm{Ca}$ e $\mathrm{Mg}$ pelo algodoeiro na condição de calagem incorporada, em comparação à calagem superficial.

Os resultados do presente trabalho evidenciam a importância de ampliar os conhecimentos sobre as interações entre as formas de aplicação de calcário e a adubação nitrogenada das culturas, por serem consideráveis seus efeitos na química do solo e na nutrição mineral das plantas, proporcionando novas estratégias de manejo da fertilidade do solo, com enfoque no sistema de semeadura direta. Dessa forma, os ânions gerados no solo via adubação nitrogenada com sulfato de amônio, em cobertura, apresentaram potencial para incrementar a oferta de cátions de caráter básico na solução da camada arável, podendo favorecer a nutrição do algodão.

\section{CONCLUSÕES}

1. O sulfato de amônio aplicado em cobertura proporcionou aumentos expressivos nas concentrações de $\mathrm{S}_{-} \mathrm{SO}_{4}{ }^{2-}$ da solução do solo na profundidade de 0 $20 \mathrm{~cm}$, independentemente da forma de aplicação do calcário. Contudo, as calagens (incorporada e superficial) não proporcionaram maior solubilização de $\mathrm{SO}_{4}{ }^{2-}$ na camada arável.

2. Nos primeiros 25 dias após a emergência do algodão, a nitrificação foi favorecida pela cobertura com sulfato de amônio somente na condição de calagem incorporada, e aos 50 dias de cultivo, as concentrações de $\mathrm{N}^{-\mathrm{NO}_{3}}{ }^{-}$da solução do solo foram aumentadas pela adubação nitrogenada, até mesmo quando não se corrigiu a acidez do solo.

3. Os teores de $\mathrm{Ca}^{2+}, \mathrm{Mg}^{2+}$ e $\mathrm{K}^{+}$da solução do solo foram incrementados pela aplicação de $\mathrm{N}$ em cobertura em todas as condições de calagem, mas a solubilização dos cátions básicos bivalentes foi bem mais expressiva quando o calcário foi incorporado.

4. O potencial do ânion $\mathrm{SO}_{4}{ }^{2-}$ em formar pares iônicos com os cátions básicos da solução do solo da camada arável foi consideravelmente superior ao do ânion $\mathrm{NO}_{3}^{-}$, pois este último sofreu forte influência da forma de aplicação de calcário.

5. A adubação nitrogenada de cobertura com sulfato de amônio proporcionou maior eficiência na absorção de $\mathrm{Ca}$ e $\mathrm{Mg}$ pelo algodoeiro na condição de calagem incorporada, em comparação à calagem superficial.

\section{LITERATURA CITADA}

ADAMS, F. \& MARTIN, J.B. Liming effects on nitrogen use and efficiency. In: HAUCK, R.D., ed. Nitrogen in crop production. Madison, American Society of Agronomy, 1984. p.417-426.

ALVAREZ V., V.H. Enxofre: critérios de diagnose para o solo e planta, correção de deficiência e excessos. In: BORKERT, C.M. \& LANTMANN, A.F., eds. Enxofre e micronutrientes na agricultura brasileira. Londrina, Empresa Brasileira de Pesquisa Agropecuária, 1988. p.3159 .

BLEVINS, R.L.; THOMAS, G.W.; SMITH, M.S.; FRYE, W.W. \& CORNELIUS, P.L. Changes in soil properties after 10 years continuous non-tilled and conventionally tilled corn. Soil Till. Res., 3:135-146, 1983.

CAIRES, E.F.; BLUM, J.; BARTH, G.; GARBUIO, F.J. \& KUSMAN, M.T. Alterações químicas do solo e resposta da soja ao calcário e gesso aplicados na implantação do sistema plantio direto. R. Bras. Ci. Solo, 27:275-286, 2003. 
CAIRES, E.F.; FONSECA, A.F.; MENDES, J.; CHUEIRI, W.A. \& MADRUGA, E.F. Produção de milho, trigo e soja em função das alterações das características químicas do solo pela aplicação de calcário e gesso na superfície, em sistema de plantio direto. R. Bras. Ci. Solo, 23:315-327, 1999.

CAMARGO, O.A. \& RAIJ, B. van. Movimento do gesso em amostras de latossolos com diferentes propriedades eletroquímicas. R. Bras. Ci. Solo, 13:275-280, 1989.

CANTARELlA, H. \& TRIVELIN, P.S.O. Determinação de nitrogênio inorgânico em solo pelo método de destilação a vapor. In: RAIJ, B. van ; ANDRADE, J.C. ; CANTARELLA, H. \& QUAGGIO, J.A., eds.. Análise química para avaliação da fertilidade de solos tropicais. Campinas, Instituto Agronômico de Campinas, 2001. p.270-276.

CARVALHO, W.A.; ESPINDOLA, C.R. \& PACCOLA, A.A. Levantamento de solos da Fazenda Experimental "Presidente Médici". Botucatu, Universidade Estadual de São Paulo, 1983. 95p.

CHAVES, J.C.D.; PAVAN, M.A. \& MIYAZAWA, M. Especiação química da solução do solo para interpretação da absorção de cálcio e alumínio por raízes de cafeeiro. Pesq. Agropec. Bras, 26:447-453, 1991.

EMPRESA BRASILEIRA DE PESQUISA AGROPECUÁRIA EMBRAPA. Centro Nacional de Pesquisa de Solos. Manual de métodos de análise de solo. 2.ed. Rio de Janeiro, 1997. 212 p.

EMPRESA BRASILEIRA DE PESQUISA AGROPECUÁRIA EMBRAPA. Centro Nacional de Pesquisa de Solos. Sistema brasileiro de classificação de solos. Rio de Janeiro, 1999. 412p.

ERNANI, P.R. \& BARBER, S.A. Composição da solução do solo e lixiviação de cátions afetadas pela aplicação de cloreto e sulfato de cálcio em um solo ácido. R. Bras. Ci. Solo, 10:41-46, 1993.

LINDSAY, W.L. Chemical equilibria in soils. New York, WileyInterscience, 1979. 449p.

MALAVOLTA, E.A.; VITTI, G.C. \& OLIVEIRA, S.A. Avaliação do estado nutricional das plantas: princípios e aplicações. Piracicaba, Potafos, 1997. 201p.

MARSCHNER, H. Mineral Nutrition of Higher Plants. London, Academic Press, 1995. 889p.

MOREIRA, F.M.S. \& SIQUEIRA, J.O. Microbiologia e bioquímica do solo. Lavras, Universidade Federal de Lavras, 2002. 626p.

OLIVEIRA, F.H.T.; NOVAIS, R.F.; ALVAREZ V., V.H.; CANTARUTTI, R.B. \& BARROS, N.F. Fertilidade do solo no sistema Plantio Direto. In: ALVAREZ V., V.H.; SCHAEFER, C.E.G.R.; BARROS, N.F.; MELLO, J.W.V. \& COSTA, L.M., eds. Tópicos em ciência do solo. Viçosa, MG, Sociedade Brasileira de Ciência do Solo, 2002. v.2 p.393-486.
PEARSON, R.W.; ABRUNA, F. \& VICENTE-CHANDLER, J. Effect of lime and nitrogen applications on downward movement of calcium and magnesium in two humid tropical soils of Puerto Rico. Soil Sci., 93:77-82, 1962.

QUAGGIO, J.A. \& RAIJ, B. van. Correção da acidez do solo. In: RAIJ, B. van; CANTARELLA, H.; QUAGGIO, J.A. \& FURLANI, A.M.C., eds. Recomendação de adubação e calagem para o estado de São Paulo. Campinas, Instituto Agronômico de Campinas \& Fundação IAC, 1996. p.1419. (Boletim técnico, 100)

RAIJ, B. van \& QUAGGIO, J.A. Métodos de análises de solo para fins de fertilidade. Campinas, Instituto Agronômico de Campinas, 1983. 31p. (Boletim técnico, 81)

RAIJ, B. van. Fertilidade do solo e adubação. Piracicaba, Ceres, Potafos, 1991. 343p.

RITCHEY, K.D.; SOUZA, D.M.G.; LOBATO, E. \& CORREA, O. Calcium leaching to increase rooting depth in brazilian savannah Oxisol. Agron. J., 72:40-44, 1980.

ROSOLEM, C.A. \& MACHADO, J.R. Efeitos da calagem e da gessagem na produção de algodão e na lixiviação de bases em dois latossolos. R. Bras. Ci. Solo, 8:103-109, 1984.

ROSOLEM, C.A.; FOLONI, J.S.S. \& OLIVEIRA, R.H. Dinâmica do nitrogênio no solo em razão da calagem e adubação nitrogenada, com palha na superfície. Pesq. Agropec. Bras, 38:301-309, 2003.

ROSOLEM, C.A.; GIOMMO, G.S. \& LAURENTI, R.L.B. Crescimento radicular e nutrição de cultivares de algodoeiro em resposta à calagem. Pesq. Agropec. Bras, 35:827-833, 2000.

SILVA, N.M. Nutrição mineral e adubação do algodoeiro no Brasil. In: CIA, E.; FREIRE, E.C. \& SANTOS, W.J., eds. Cultura do algodoeiro. Piracicaba, Potafos, 1999. p.57-89.

SILVA, N.M.; CARVALHO, L.H. \& QUAGGIO, J.A. Ensaio de longa duração com calcário e cloreto de potássio na cultura do algodoeiro. Bragantia, 54:353-360, 1995.

SPOSITO, G. The chemistry of soil. New York, Oxford University Press, 1989, 277p.

STRONG, D.T.; SALE, P.W.G. \& HELYAR, K.R. Initial soil pH affects the $\mathrm{pH}$ at which nitrification ceases due to selfinduced acidification of microbial microsites. Austr. J. Soil Res., 35:565-570, 1997.

VIEIRA, R.F. \& RAMOS, M.M. Fertirrigação. In: RIBEIRO, A.C.; GUIMARÃES, P.T.G. \& ALVAREZ V., V.H., eds. Recomendações para o uso de corretivos e fertilizantes em Minas Gerais: $5^{\mathrm{a}}$ aproximação. Viçosa, MG, Comissão de Fertilidade do Solo do Estado de Minas Gerais, 1999. p.111-130.

VITTI, G.C.; FERREIRA, M.E. \& MALAVOLTA, E. Respostas de culturas anuais e perenes ao fosfogesso. In: SEMINÁRIO SOBRE O USO DE FOSFOGESSO NA AGRICULTURA, 1. Brasília, 1985. Anais. Brasília, Empresa Brasileira de Pesquisa Agropecuária, 1986. p.17-44. 